\title{
TEMPORAL ARTERITIS: A REPORT OF THREE CASES
}

\author{
BY \\ HENRY COHEN \\ Department of Medicine, University of Liverpool \\ AND \\ C. V. HARRISON \\ Postgraduate Medical School of London
}

(RECEIVED FOR PUBLICATION, JUNE 22, 1948)

This disease, which has also been described as cranial arteritis and giant-cell arteritis, was first established as a clinical and pathological entity by Horton and others (1934), though there is evidence that single cases were described before this (Andersen, 1947). Since 1934, over seventy cases have been reported in the literature from U.S.A., Great Britain, France, and Scandinavia. These have been reviewed and analysed elsewhere in this issue (Harrison, 1948). The disease runs a characteristic clinical course, and the affected vessels have a characteristic morphology. Although the earlier recorded cases ran a completely benign course, those subsequently reported have shown that involvement of other vessels may cause blindness, cerebral damage, and even death.

The three cases reported here exemplify the characteristic clinical course and morphology of the disease, and also illustrate some of its complications.

\section{Case Reports}

Case 1.-A coach builder, aged 72 , from a country district of North Wales was admitted to hospital with a three months' history of shooting pains in both sides of his head. The pain was at first intermittent and located behind the left ear, but later it became almost continuous and spread to the front and back of the head. Six weeks before admission the pain moved to the right temple and came in bursts of great severity alternating with a continuous dull ache. Bending down made the pain worse but coughing and eating did not. During the two weeks before admission the pains had eased a little. On examination he was a well-nourished man with normal temperature and pulse; his face showed leucoderma. Both superficial temporal arteries were visibly prominent but no longer tender. There was no pulsation in ei:her. Physical examination (blood pressure $148 / 80 \mathrm{~mm}$. Hg.), blood count, electrocardiogram, and radiograph of the chest all gave negative results.
A segment of the right superficial temporal artery was excised, and this appeared to relieve the pain. After nineteen days in hospital, that is, about 15 weeks after the onset of symptoms, the patient was discharged much improved.

Histology (Plate VIa and b).-The lumen was reduced to a small slit by intimal proliferation, but there was no thrombosis. The intimal thickening was composed of a cellular connective tissue containing fibroblast nuclei but very few inflammatory cells. The media was intact around approximately two-thirds of the circumference and was infiltrated by a few inflammatory cells. In the remaining third it was totally replaced by a cellular infiltration of macrophages, lymphocytes, and polymorphonuclears, though there was no remaining necrotic tissue. The internal elastic lamina was fragmented, and there were a few giant cells in the vicinity of the broken elastic fibres. The adventitia was fibrosed, forming a thickened collagenous coat, and several nerves were embedded in it. It did not, however, show any appreciable cellular reaction.

Case 2.-A farmer aged 65 years was admitted complaining of headaches. Six weeks before admission he felt ill and took to bed and thought that he was febrile. Soon after this he developed headaches all over his head but worse on the left side. This was aggravated by coughing and was severe enough to interfere with sleep. He had lost about 1 stone in weight since the onset of his illness. On examination he was found to be well preserved, but he showed signs of recent loss of weight. He had some pyrexia (98 to $101^{\circ} \mathrm{F}$.) on admission, but this settled to normal in a few days. The temporal arteries were tortuous, thick, and tender, but pulsating. Blood pressure was $120 / 80 \mathrm{~mm}$. Hg. Abduction of the right shoulder was limited and the right deltoid wasted. Physical examination was otherwise negative. Blood examination revealed $\mathrm{Hb} 75$ per cent, red blood cells $4,400,000$, white cells 12,800 per c.mm. of blood, with 73 per cent polymorphs. The erythrocyte sedimentation rate was $10 \mathrm{~mm}$. in 1 hour (Wintrobe-corrected), the 


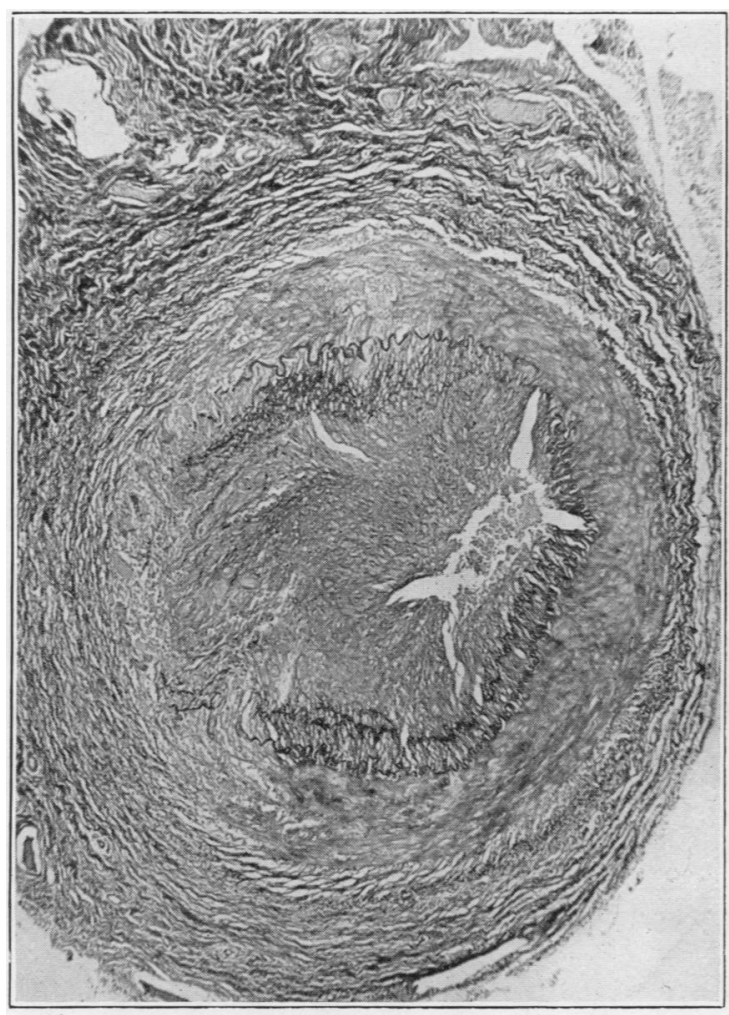

(a)

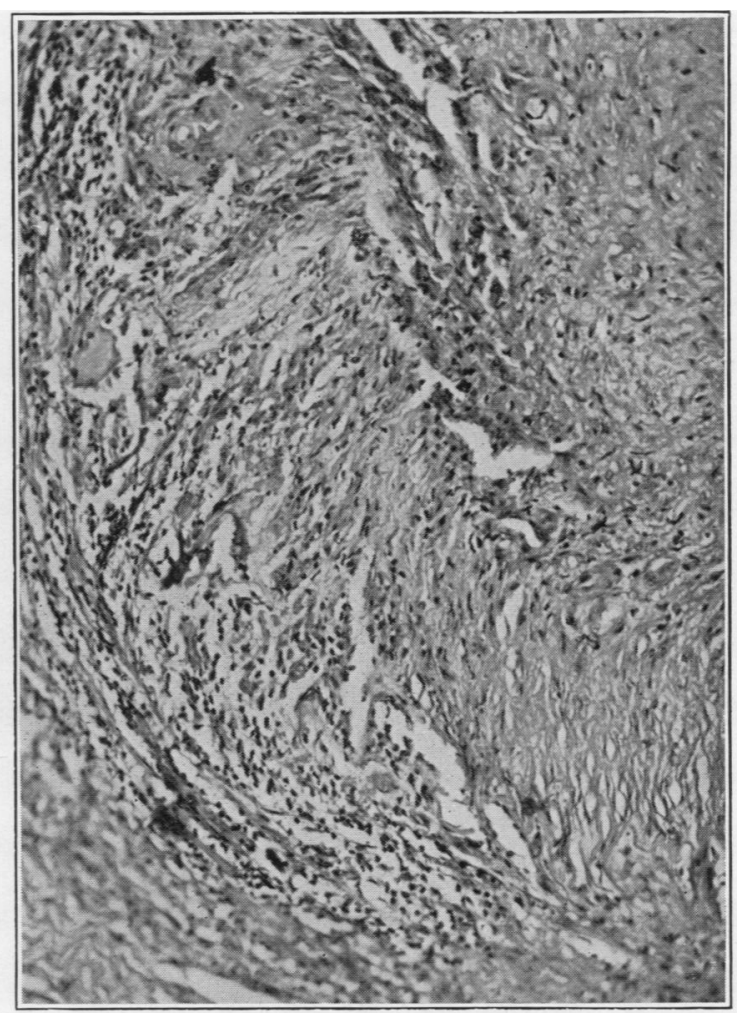

(b)

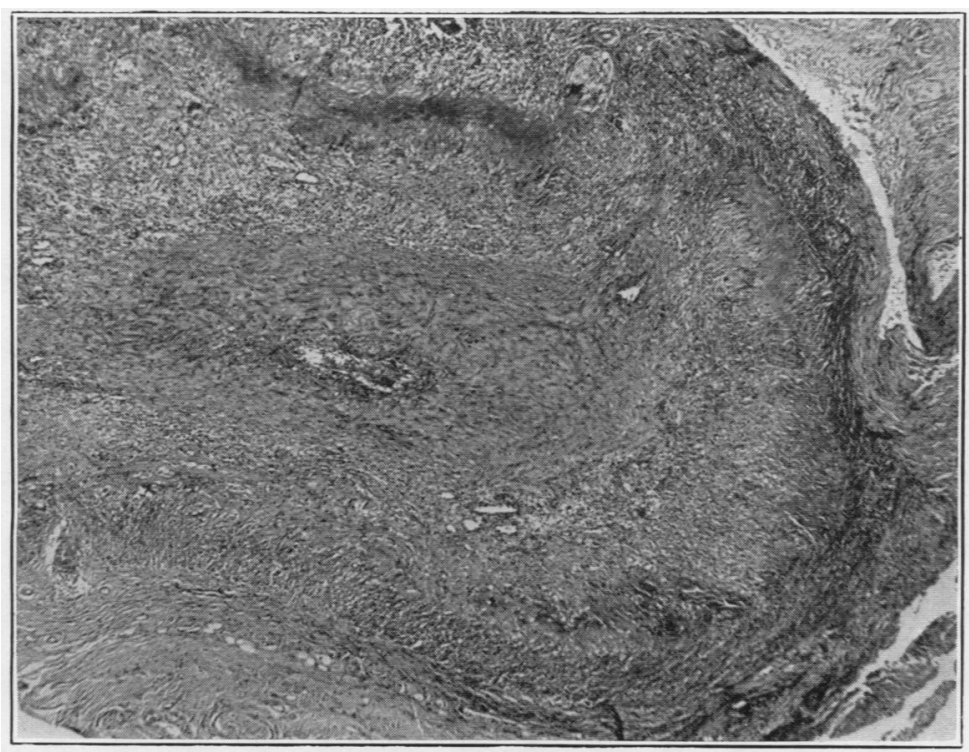

(c)
Plate VI.-(a). Case 1. Transverse section of temporal artery showing extreme intimal proliferation. In the segment on the left the media is largely destroyed and the elastica is interrupted. The adventitia is fibrosed. (Verhoeff and Van Gieson, $\times$ 50.) (b). Case 1. High-power magnification of part of $(a)$, showing the cellular infiltration spreading through media. A giant cell is shown near the left side. (Haematoxylin and eosin, $x$ 140.) (c). Case 2 . Slightly oblique section. The intima is enormously thickened and the inner fibrous and outer granulomatous layers are shown. The media is well seen near the lower border but is necrotic near the upper border. The adventitia is fibrosed, and a small nerve is visible at the extreme lower edge. (Haematoxylin and eosin, $\times$ 38.) 


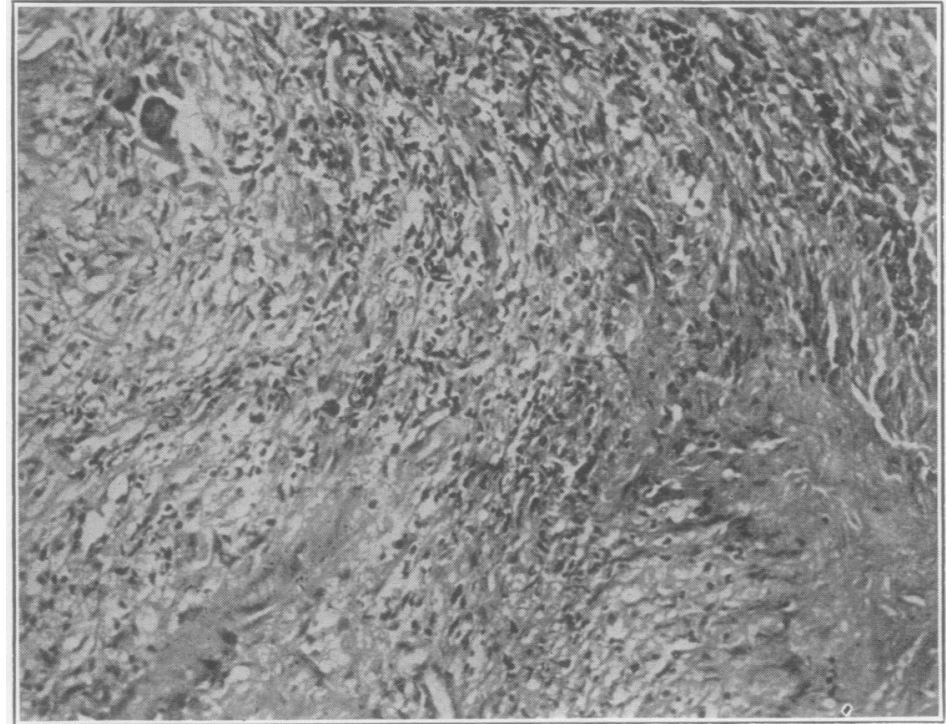

(a)
Plate VII.-(a). Case 2. Higher magnification of part of Plate VIc, showing $\stackrel{\rho}{+}$ granulomatous replacemen $t$ of media spreading into intima (lower $\frac{\bar{\sigma}}{\sigma}$ left). Two giant cells are seen near $\overline{\bar{c}}$ the top left corner. (Haematoxy- $\vec{T}$ lin and eosin, $\times$ 190.) (b). Case 3. Transverse section just beyond a bifurcation. The greatly thickened intima is composed of loose con- $\overrightarrow{0}$ nective tissue. The media is infil- $-\rightarrow$ trated by cells, and the adventitia $\vec{\omega}$ is fibrosed. (Verhoeff and Van Gieson, $\times$ 45.) (c). Case 3. Higher $\frac{?}{0}$ magnification of part of $(b)$. The intima lies to the left and the media $\vec{A}$ to the right, separated by a wavy iv black elastic lamina. Note the $\vec{N}$ numerous giant cells in the media. (Verhoeff and Van Gieson, $\times$ 120.)

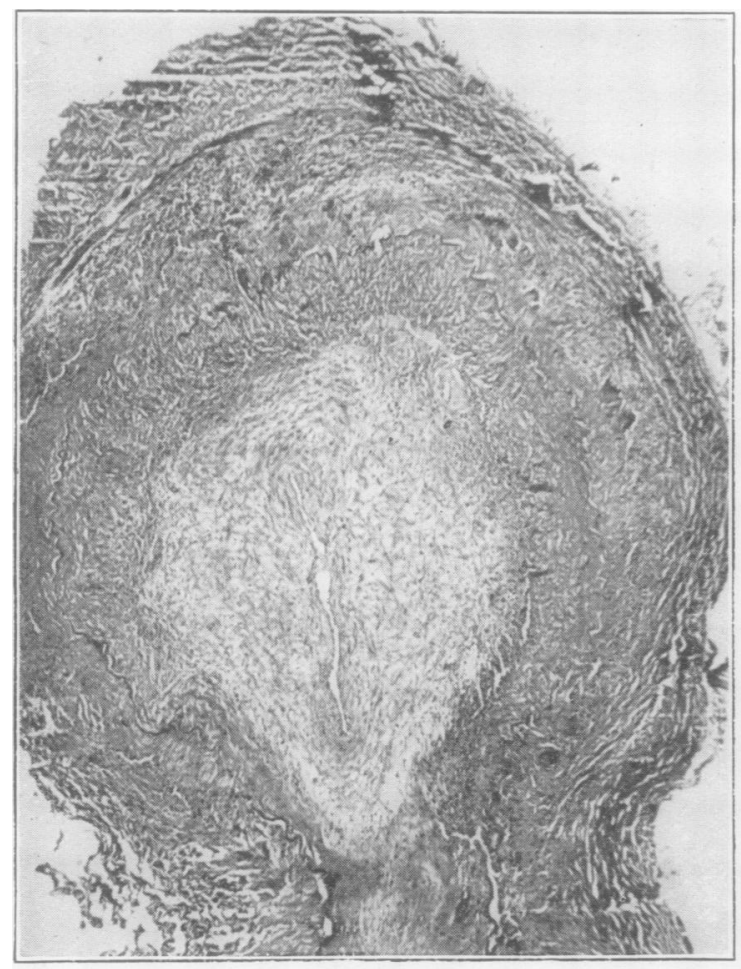

(b)

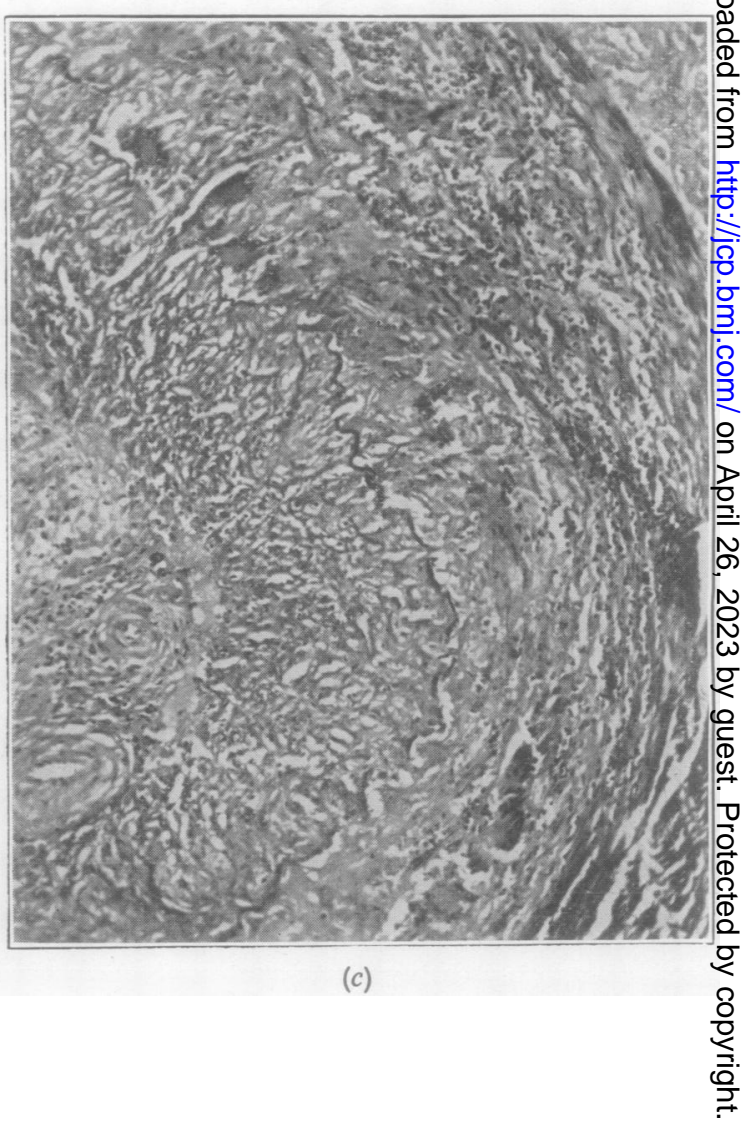


Wassermann reaction negative, and the cerebrospinal fluid normal.

A week after admission a segment of the left temporal artery was excised and this was followed by relief of the headache. A fortnight after admission, eight weeks after the onset of the illness, the patient was discharged free from pain. Six months later he died suddenly from coronary occlusion: no autopsy was performed.

Histology (Plates V, VIc, and VIIa).-The lumen was reduced to a slit $0.1 \times 0.5 \mathrm{~mm}$. but was free from thrombus. The intima was greatly thickened and consisted of two layers. The inner was composed of mucoid connective tissue with fairly numerous fibroblast nuclei but very few inflammatory cells; the outer consisted of granulation tissue with numerous capillaries and fibroblasts and heavily infiltrated with polymorphonuclears and macrophages. The media around approximately half the circumference was necrotic; and the rest, though containing muscle fibres, was heavily infiltrated by polymorphonuclears, lymphocytes, and macrophages. The internal elastic lamina was disrupted, and there was a number of giant cells. The adventitia was fibrosed but contained few inflammatory cells. Several small nerves were embedded in the fibrous tissue. A small branch of the temporal artery included in the biopsy showed exactly the same lesion as the parent vessel. A biopsy of calf muscle did not show any vascular lesion.

Case 3.-A farmer aged 69, and a neighbour of Case 2, was admitted complaining of headache and blindness in one eye. Five months before admission he developed severe pain in the right side of his head; a fortnight later he suddenly developed diplopia for five minutes and then lost the sight in the left eye. A fortnight later the pain on the right cleared up but soon returned on the left side, and he noticed a "swollen vein" in his left temple, which he said was not tender. Two months after the onset of the illness the pain returned to the right side and persisted there till admission. It was severe enough to interfere with sleep.

On examination he was seen to be a wasted elderly man, apyrexial, but with a pulse rate of 100 to 120 per minute. The left superficial temporal artery was thick and tortuous but not tender. The right temporal artery was not palpable. The left eye was blind except for appreciation of light and dark; the disc was pale and there were signs of thrombosis of the central retinal artery. The blood pressure was 175/ $80 \mathrm{~mm} . \mathrm{Hg}$, and there were signs of generalized arteriosclerosis with some myocardial ischaemia. The sedimentation rate was $32 \mathrm{~mm}$. in one hour (Wintrobecorrected). The blood count showed $\mathrm{Hb} 90$ per cent, red blood cells $4,300,000$ and white cells 6,200 per c.mm. The cerebrospinal fluid was normal.

A segment of the left temporal artery was excised and this was followed by relief of his pain. He was discharged free from symptoms a fortnight after admission: five and a half months after the onset of his illness.
Histology (Plates IVa and b, VIIb and c).-The specimen consisted of a $\mathrm{Y}$-shaped segment and was cut to show transverse sections of the two limbs. These were exactly similar. The lumen was patent but reduced to a narrow slit. The intima was greatly thickened and consisted of mucoid connective tissue with frequent fibroblast nuclei but very few inflammatory cells. The media was free from any gross necrosis but was largely destroyed by a granulomatous mass consisting of young capillaries, polymorphonuclears, lymphocytes, and a few macrophages. Giant cells were numerous. This acute inflammatory reaction spread into the immediately adjacent intima and adventitia, but only for very short distances. The internal elastic lamina was broken up into a line of short fragments. Only the inner part of the adventitia was ircluded in the biopsy, but this showed some fibrous thickening. No nerves were included.

\section{Comment}

The present cases were all in males, though in the recorded cases there have bzen slightly more women than men (Andersen, 1947 ; Cooke and others, 1946). The ages of the present cases, $72,65,69$, are in accordance with the usual findings, most recorded cases being over 60 .

It is of interest that our three cases were country dwellers, and two were neighbouring farmers admitted within three months of each other. Horton and others (1934) drew attention to the fact that their early cases were farmers or country dwellers, though in most of the subsequent publications the patients have either been town dwellers or this information has not been given.

The duration of the disease in our cases was 15,8 , and 23 weeks, which is shorter than the average (about six months) of previously recorded cases. But it is within the range of duration of such cases, which has varied from seven or eight weeks (Hoyt and others, 1941; Sproul, 1942) up to two years' (Cooke and others, 1946).

In this series Case 1 recovered completely. Case 3 also recovered but was left with blindness in his left eye. Case 2 died from myocardial infarction, six months after discharge. An autopsy was not performed, and we do not know whether death was due to arteritis affecting the coronary arteries or to coincidental atheroma. Of the published cases, a number have died within some months of discharge, mostly from myocardial ischaemia or cerebral vascular disease. (Chasnoff and Vorzimer, 1944; Curtis, 1946; Kilbourne and Wolff, 1946). Other cases (Cooke and others, 1946) have died during the course of the disease from cerebral ischaemia due to arteritis of the cranial arteries and the diagnosis confirmed at autopsy. 
In the first of the three cases here recorded the lesion appeared to be limited to the temporal arteries; in Case 2 the right circumflex artery was involved, and in Case 3 there was blindness in the left eye due to thrombosis of the central retinal artery. In the early reports it was suggested that the disease was a localized one, but Jennings (1938) described blindness as a complication presumably due to involvement of the retinal vessels, and similar cases have since been reported by Dick and Freeman (1940), Scott and Maxwell (1941), Cooke and others (1946), Shannon and Solomon (1945), Robertson (1947), and Curtis (1946). The cases that have come to autopsy have shown involvement of other vessels.

That the disease is not a localized process is suggested by the frequent occurrence of pyrexia and pains in body and limbs, and a degree of systemic illness out of proportion to the physical findings. Case 2 of the present series was pyrexial and was sufficiently ill to take to bed. The outstanding symptom in our three cases, and in all the recorded cases, has been pain in the head. This is of great severity and is usually resistant to analgesics. Many forms of therapy have been tried but none has been constantly successful. Removal of a segment of the affected temporal artery for biopsy has quite frequently been followed by relief of pain. This was noted by Horton and Magath (1937) and has since been confirmed by numerous other workers, and from the literature it appears to be the most constantly successful form of therapy. It was certainly of value in relieving symptoms in the present three cases. It has been suggested that this is due to interruption of the accompanying nerves, and
Lucien and others (1939) described such nerves embedded in the fibrosed adventitia. We have also noted nerve fibres embedded in the fibrosed adventitia of our first and second cases.

Nothing is known of the aetiology of the disease and, though many of the clinical features suggest an infective cause, so far all attempts to isolate an organism have been fruitless. Nevertheless the disease presents a uniform pattern which differentiates it from polyarteritis nodosa or Bürger's disease. It has a different anatomical and age incidence and a better prognosis. The histology of the lesions is also different though in some ways less characteristic. Almost any of the individual histological features of temporal arteritis may be found in either polyarteritis or Bürger's disease, yet the whole picture is sufficiently distinctive to be recognizably different (Gilmour, 1941 ; Cooke and others, 1946).

We are indebted to Mr. F. Beckwith for the photomicrographs.

\section{REFERENCES}

Andersen, T. (1947). Act. med. scand., 128, 151.

Chasnoff, J., and Vorzimer, J. J. (1944). Ann. intern. Med., $20,327$. Cooke, W. T., Cloake, P. C. P., Govan, A. D. T., and Colbeck, J. C. (1946). Quart J. Med., n.s. 15, 47.

Curtis, H. C. (1946). Amer. J. Med., 1, 437.

Dick, G. F., and Freeman, G. (1940). J. Amer. med. Ass., 114, 645. Gilmour, J. R. (1941). J. Path. Bact., 53, 263.

Harrison, C. V. (1948). J. clin. Path., 1, 197.

Horton, B. T., Magath, T. B., and Brown, G. E. (1934). Arch. intern. Med., 53, 400 .

Horton, B. T., and Magath, T. B. (1937). Proc. Mayo Clin., 12, 548.

Hoyt, L. H., Perera, G. A., and Kauvar, A. J. (1941). New Engl. J. Med., 225, 283.

Jennings, G. H. (1938). Lancet, 1, 424.

Kilbourne, E. D., and Wolff, H. G. (1946). Ann. intern. Med., $24,1$.

Lucien, M., Mathieu, L., and Verain, M. (1939). Arch. Mal. Coeur, $32,603$.

Robertson, K. (1947), Brit. med. J., 2, 168.

Scott, T., and Maxwell, E. S. (1941). Internat. Clin., 2, 220.

Shannon, E. W., and Solomon, J. (1945). J. Amer. med. Ass., 127, 647.

Sproul, E. E. (1942). N.Y.St. J. Med., 42, 345. 